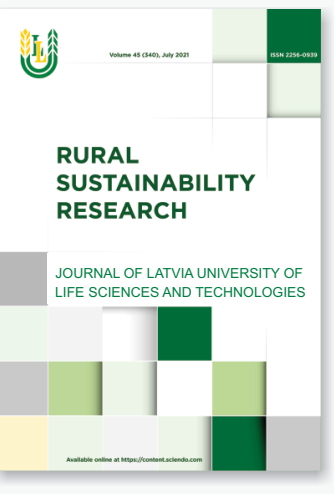

\title{
Green Transportation in the Šiauliai Regional Companies
}

\author{
Ineta Beniušiené, *Aida Jankauskienè \\ Vilnius University Šiauliai Academy, 38 P. Višinskio g., Šiauliai, Lithuania
}

\begin{abstract}
A relevant and practical research object is analysed in the article - the implementation resolution of green transportation and the benefits of using such means. In this article, object is analysed from the interdisciplinary position, i.e. from the perspective of transportation, one of the logistical subsystems, and sustainable environment. The transportation department is undoubtedly an important guarantor of economic and industrial development. Despite the worldwide importance of transportation in everyday activities, the transportation also poses the risk for human health and life quality, for it is one of the biggest consumer of oil products and significantly contributes towards air pollution. Despite many theoretical and empirical researches, Šiauliai region still lacks an approach towards the implementation possibilities and studies revealing the benefits of green transportation. A comparative analysis has been performed by using the survey data, collected from 402 workers, responsible for transportation, working for Siauliai regional companies. According to the results of the research for implementation situations of green transport in Siauliai regional companies, the representatives of regional companies understand the importance of green transport, and more and more companies aim to reduce the environmental risk and to become more competitive. Integrated transportation by combining several means of transport, cargo consolidation by combining small orders and big orders, and ecological driving are the green transportation measures implemented most in regional companies. The typical benefits of green transport are increased environmental friendliness and improved relationship with consumers.
\end{abstract}

Key words: Green transport, green transportation, benefits of green transportation.

\section{Introduction}

People use green transportation not just because of ecology, to reduce pollution and traffic jam, to save on transport costs, but also due to competitive advantage. Consumers require companies to become socially responsible and for their activity to become green. According to Kengpol, Tuammee (2016), Lai et al. (2012), the aim of using green transportation is to reduce negative environmental effect and to achieve a balance between economic, environmental and social effectiveness. Zhang et al. (2015) mention these benefits of implementing green transportation: economic (minimizing the cost, maximizing the profit); social (encouragement of green consuming, satisfaction of consumers, organizational commitment); environmental (reducing pollution, reducing carbon footprint, reducing energy consumption, waste collecting).

Multiple studies reveal that more and more companies get into green transportation in order to reduce environmental risk and to be more competitive (Saroha, 2014; SerokaStolka, 2014; Pan, 2012; Dey, LaGuardia \& Srinivasan, 2011; Pazirandeh \& Jafari, 2013). Green transportation is not widely analysed in Lithuanian science papers, and not just Lithuanian, but also regional research of green transport in companies is found lacking. The aim of green transportation is to encourage social responsibility by reducing traffic jam, environmental pollution.

The implementation of the concept of green transportation in the companies is considered as measures for increasing competitiveness of the organization in the current economic, social and environmental context. All this encourages to look for answers to problem questions: how is green transportation used in Šiauliai regional companies? How do companies benefit from using green transportation?

The aim of the article is to identify the green transportation and the benefits of implementing it in Siauliai regional companies. 
According to the research by Gechevski (2016), it is not only the increasing fuel, energy, raw material expenses, but also an increasing level of $\mathrm{CO}$ and climate change, as well as an increasing awareness in the environmental problems area, encouraging companies to look for alternative green solutions. The companies must transfer to more ecological transport due to air pollution, greenhouse gas, excavation of natural resources, and increase in oil prices (Panday \& Bansal, 2014), because the transport has the biggest effect on the environment (Dekker et al., 2012, Pazirandehet et al., 2013). The biggest negative effect towards the environment comes from the capacity, noise level, traffic safety and fuel cost of the transport. According to the White Book of Lithuanian Regional Politics (2017), i.e. the main document of European Union transport politics, listing the most important goals of transport and logistics departments, with the purpose of better exploitation of modern infrastructure and reducing negative environmental effects, there is a possibility of increasing the effectiveness of car fuel usage while creating and using sustainable fuel, to optimize the logistics of multimodal transport through more efficient use of modes of transport. Companies reform their transportation activities to use their resources more effectively and to save the environment. The basis of green transportation is to ensure the balance between environmental actions and competitive advantage (Tuzun Rad \& Gulmez, 2017). Green transportation is the management of ecological transportation that saves the environment, encourages economic and social development. Using this method, it is possible to achieve lower fuel usage or to completely change it to biomass; it is also possible to use transport that uses natural resources as fuel (Karia et al., 2016).

Xuezhong et al. (2011) notes, that green transportation of a cargo cannot be limited by green transportation to the consumer only, it must include the four lines of transportation: 1) green transportation from the manufacturer to the distributors; 2) green transportation from the manufacturer to the distributors, with the help of external logistics service provider; 3 ) green transportation from the distributor to the final consumer; 4) green transportation from the distributor to the final consumer, with the help of external logistics service provider. Zhang et al. (2015) notes that the manufacturers, distributors and the external logistics service provider usually agree to coordinate their processes together while performing green transportation operations. According to Xuezhong et al. (2011), green transportation operations should be carried out by creating a shared electronic information system, by using green transportation, and selecting an appropriate and reasonable way of delivery.

To summarize the research by scientists, it is possible to say that the aim of green transportation is to increase an effective cargo transportation using an effective route, creating the conditions to ensure safety and more sustainable environment while transporting partial cargo. The aim is to reduce pollution in social, ecological and economic level.

Dekker, Bloemhof \& Mallidis (2012), Pazirandeh et al. (2013) note that in the supply chain, transport has the biggest effect towards the environment. Air and road cargo transportation pollutes environment the most, so, in order to reduce the transport pollution, it is important to select a proper, integrated, way of transportation that combines multiple types of transport. According to Nylund (2012), transport is the main consumer of fossil fuels, which means that it emits many toxic and chemical emissions, which is why combining different types of transport contributes towards saving environment through an effective use of transportation. According to Nathanail et al. (2020), one of the most important economic departments, i.e. the transportation department, would reduce environmental pollution by selecting a rational method of distribution.

The research by Saroha (2017) showed that one of the main reasons why transport companies use green transportation is the aim of competitive advantage in the market, and the companies always try to use newer and ecological means of transport. The use of more ecological trucks allows the reduction of pollution, encourages social and harmonious activities and reduces the expenses. Ecological transport is a double energy transport, one that is driven by the use of natural gas, electricity or hydrogen and solar energy. Han-Ru (2016) presents green transportation as a comfortable, safe, useful system with minimal pollution. The creation of ecological transport system is beneficial for the intensive road use in order to lessen the traffic jam, reduce energy consumption, amount of emissions, amount of greenhouse gas, and to improve air quality.

McKinnon (2010) has performed a research in Finland and determined that new trucks use 5-15\% less fuel compared to older trucks while transporting cargo. In order to reduce the pollution in transportation department, it is also important to use power sources that emit less carbon dioxide: to use renewable sources of energy, nuclear energy, to adapt carbon dioxide $\left(\mathrm{CO}_{2}\right)$ collecting and holding technologies in the fossil fuel plants.

Based on scientific research, companies could reduce their transportation demand by transporting consolidated cargo. In this case, small orders are combined with large ones, and in order to reach the maximum benefits, they are transported not only in small distances, but in large ones too. Cargo consolidation allows connecting several small packages that are meant to be delivered to the same place, and deliver them all in one transport. According to Donohoe (2019), there is no difference between small business delivering packages to customers or transporting goods to the storage, cargo consolidation helps to save time and money. Consolidation allows reducing cargo rates, because the truck space is shared with other senders. That way both the fuel costs and the overall transportation cost determined to the customers based on cargo weight, are reduced. For that purpose, companies are encouraged to use informational technologies, which would help in determining more effective routes (Kumar et al., 2012) by serving several, not just one, customer in one route. According to Saroha (2017), cargo consolidation helps in avoiding traffic jam in the cities and reducing pollution at the same time. According to the research, cargo consolidation not only helps in reducing pollution, it also reduces shipping costs and increases safety.

According to Zhang (2015), to ensure a successful implementation of green transportation, it is necessary to try to cooperate with partners. As noted by Ammiruddin (2020), cooperation is beneficent for companies with small supply chains. Cooperating with partner carriers greatly reduces the transportation expenses and allows controlling the course of package right until it reaches the customer. In order to reach the effectiveness of transport, companies must often cooperate and share the transport capacity (McKinon, 2010).

Valančiūtè-Tonkevičienè et al. (2016) have noted that 
another not less important means of green transportation is ecological driving (anticipating the traffic, keeping a consistent speed, early gear shifting, measuring the tire pressure). When teaching the drivers to drive ecologically, traffic safety is increased, the greenhouse effect from air pollution and environmental noise level is reduced, fuel consumption is reduced, and social responsibility is increased. According to Garcia-Castro et al. (2014), the main conception of ecological driving is driving to reduce fuel consumption, which, in turn, reduces $\mathrm{CO}_{2}$ emission. Based on a research by Kim et al. (2015), with a major increase in a number of vehicles all over the world, we are approaching a very dangerous level of emissions. Ecological driving could be a solution when aiming to save energy, reduce the amount of carbon dioxide and to join the efforts in reducing global warming.

The scientific research by McKinon (2010) showed that one of the most important actions, influencing the loading of vehicles, is the connection between transport and other activity. Companies prioritize these activities more often than the effectiveness of the transport. It is more important for companies to return a broken or unneeded product as soon as possible, because they do not want to store a returned product and wait until they can ship a fully loaded vehicle. Companies must be more responsible when it comes to this and find a place in their storage, which would allow them to avoid additional expenses for sending not fully loaded trucks, thus causing a bigger negative impact towards the environment. Management of returned products must be directed towards reduction of needs for transportation.

The implementing measures and benefits of green transportation, as seen in scientific literature, are summarized in Table 1.

\section{The implementing measures and benefits of green transportation}

Table 1

\begin{tabular}{|l|l|}
\hline Measures & Economic, ecological, social benefits \\
\hline Integrated transportation & Reduced emission of harmful substances \\
\hline More ecological transport & Reduced pollution \\
\hline Newer transport & Reduced fuel consumption \\
\hline Cargo consolidation & Reduced operating costs of the company \\
\hline Effective route planning & Optimized distribution flows \\
\hline $\begin{array}{l}\text { Purchase of intermediary } \\
\text { services }\end{array}$ & Improved results of the activity \\
\hline Ecological driving & Improved company image \\
\hline $\begin{array}{l}\text { Management of the product } \\
\text { return }\end{array}$ & Improved cooperation with other participants in the market \\
\hline $\begin{array}{l}\text { Cargo distribution stations } \\
\text { outside the city }\end{array}$ & Competitive advantage is gained \\
\hline
\end{tabular}

Source: authors creation based on McKinon, 2010; Xuezhong et al., 2011; Denisa et al., 2015; Mala et al., 2017; Tuzun Rad et al., 2017; Zaman et al., 2017.

To summarize the research performed by scientists (McKinon, 2010; Xuezhong et al., 2011; Denisa et al., 2015; Mala et al., 2017; Tuzun Rad et al., 2017; Zaman et al., 2017), the importance of transportation in everyday activities keeps increasing every year, despite the danger it poses to human health and life quality. In order to reduce this danger, companies implement green transportation, which reduces pollution, harmful emissions and allows to save the environment for future generations. The companies, trying to reduce environmental pollution, try to optimize route flows, effectively plan the routes, and choose an integrated, combined, multimodal way of distribution. The use of more ecological, newer trucks would allow the reduction of pollution, traffic jam, encourage a social harmonious activity and reduce fuel consumption and expenses. Cooperation with partner carriers would allow to reduce transportation expenses and to control the shipment right until it reaches the customer. Based on multiple studies, when teaching the drivers to drive ecologically, traffic safety is increased, the greenhouse effect, from air pollution, and environmental noise level is reduced, fuel consumption is reduced, and social responsibility is increased.

The green transportation implementation measures, as noted in scientific literature, are complementary, encouraging cooperation and business social responsibility between groups of different interests. All of the interest groups are responsible for the well-being of the country by ensuring a sustainable environment, however, it can be said, that the business gets the biggest responsibility to turn its resources and abilities towards a sustainable environment and to change their usual behaviour.

\section{Materials and Methods}

A scientific literary analysis and a written survey $(n=402)$ were performed in order to reveal the importance of green transportation, the implementation and benefits in Šiauliai 
regional companies, and the importance and expression of green transportation in population by identifying the benefit ratings of them, depending on the company characteristics.

Siauliai region - a region that has a significant place in the economic, social and cultural life of the country, which has created a competitive economy and reached a greater social cohesion in society. Šiauliai region consists of 7 municipalities, the total area is $8537 \mathrm{~km}^{2}$, population 261429 (in 2020). In January 2020, there were 77.8 thousand drivers of heavy goods vehicles and lorries, but by July 1st the number of these workers has been reduced to 74.1 thousand in this department. It is not only the number of workers that was reduced in transportation department. As of March 2020, there were 4577 companies in the Department of Transportation and Logistics in Lithuania, and this number had been reduced every month and there were 4498 companies by September. This means, that the department had been reduced by 79 companies within 6 months. However, based on an overview of the economic structure and development of Śiauliai region in 2020, the transportation and storage activities had been increased by 25 companies or $3.8 \%$. The number of transported goods was increasing in all the regions of Lithuania, there were 25629.3 thousand tons of cargo within the first quarter of the year 2020, and in the year 2021 during the same period, this rate has increased to 28982.9 thousand tons. The reduced number of workers could be assessed as a positive change, it shows that business is rearranging companies, looking for solutions that are more conductive and distributes the funds in a way that is more effective. The increased number of transported goods shows the increase of economy, as well as an increased need for road transportation, which means increased environment pollution. This shows that green transportation should become the goal of every region in Lithuania, including the Šiauliai region.

Research instrument. The questionnaire consists of demographic bloc (professional and general characteristics of companies), a two-part diagnostic bloc (the application and benefits of green transportation). The statements provided in diagnostic bloc allow the assessment (McKinnon 2010; Xuezhong et al. , 2011; Dekker et al., 2012; Dekker et al., 2012; Pazirandehet et al., 2013; Garcia-Castro et al., 2014; Kim et al., 2015; Zhang et al., 2015; Han-Ru, 2016; Nathanail et al., 2020; Ammiruddin, 2020) and the benefits (McKinon, 2010; Xuezhong et al., 2011; Denisa et al., 2015; Mala et al., 2017; Tuzun Rad et al., 2017; Zaman et al., 2017, etc.) of green logistics.

Survey sample. A targeted selection of respondents has been chosen. Selection criteria of respondents: responsibility for the logistical activities in the company. The imposition of such criteria was necessary, because it is likely that other employees of the organization may not have enough knowledge on the situation for application of green logistics. An important research quality criterion is representativeness of sample. In order to determine the representative sample of the research, it is important to know the statistical population.

In this case, the statistical population is the representative of all Siauliai regional companies. According to the Lithuanian Department of Statistics, there were 7636 economic subjects in the beginning of the year 2020. After choosing the $95 \%$ possibility and $5 \%$ error, the determined survey sample is 366 respondents. In order to reveal the situation of green transportation in Šiauliai regional companies in more detail, there were 402 regional companies that answered the questions, out of which $31.6 \%$ were manufacturing companies, $33.8 \%$ - trading companies, and $34.6 \%$ - service companies. These groups were chosen due to the fact, that all of these companies perform logistic processes. Trading companies were distinguished in a separate segment so they could be identified, because trading companies, most of the time, do not identify with service-providing companies. Very small companies (up to 10 workers) consist of $48 \%$ from all the companies in survey, small companies (10-49 workers) $31.1 \%$, medium sized (50-249 workers) $-14.2 \%$, while large companies with over 250 workers $-6.7 \%$ of all surveyed companies. Distribution of the companies based on income also varies: companies with income of less than 100,000 EUR consist of $42.5 \%, 100,001-500,000$ EUR - 31.6\%, 500,001-1000,000 EUR - 10.9\%, and companies receiving over 1000,001 EUR $-11.0 \%$ of all the surveyed companies. 16 companies that have participated in the research (4\%) did not provide their yearly income.

Limitations of research. The results of the research can be generalized by the analysed Šiauliai regional companies. The results of the research represent the implementation and benefits of green transportation in Siauliai regional companies. The results of the research can be generalized only in the researched population, and the generalization in a wider context would require additional research.

\section{Results and Discussion}

According to scientific research, transportation process is the most environmentally sensitive and has the biggest negative impact. In order to reduce the amount of pollution in transport department, they are suggested to use ecological, newer transport, to apply multimodal transportation, consolidate cargo, and use intermediary services and to raise ecological driving.

According to the results of the research of Implementation situations of green transportation in Šiauliai regional companies, the representatives of regional companies understand the importance of green transportation, $67.72 \%$ of the research participants think these measures are important. $24.41 \%$ of the regional company representatives that have participated in the research think that green transportation is moderately important. $3.15 \%$ of the Śiauliai regional company representatives have said that these measures are very important, and the same part of respondents said, that it was not important at all. It is possible, that the importance rating of green transportation is related to the professional characteristics of the respondents and general characteristics of the companies. Correlation tests were performed in order to confirm or deny this (see Table 2). 
The connection between the importance of rating of green transportation and the professional characteristics of the respondents and general characteristics of the companies

\begin{tabular}{|c|c|}
\hline Characteristics of the respondents & Meaning \\
\hline Position & $p=0.000$ \\
\hline Work experience & $p=0.057$ \\
\hline Main activity & $p=0.210$ \\
\hline Number of workers & $p=0.020$ \\
\hline Yearly income & $p=0.034$ \\
\hline
\end{tabular}

The connection is considered significant if the significance $(p)$ does not exceed the significance level 0.05 . After determining, that the significant rating difference of the importance of green transportation depends on the position, number of workers, and yearly income of the respondents, the average estimates of importance were calculated for these groups (see Table 3). The average estimates of importance are calculated by giving points to the estimates ("very important" -5 points, "important" -4 points, "moderately important" - 3 points, "not important" - 2 points, "not important at all" - 1 point).

\section{The average ratings of the importance of green transportation based on separate groups of respondents}

\begin{tabular}{|l|l|c|}
\hline \multicolumn{2}{|c|}{ Professional characteristics of the respondents } & $\begin{array}{c}\text { Average estimates in } \\
\text { points }\end{array}$ \\
\hline \multirow{4}{*}{ Position } & Top level manager & 4.03 \\
\cline { 2 - 3 } & Middle level manager & 3.74 \\
\cline { 2 - 3 } & Lower level manager & 3.00 \\
\cline { 2 - 3 } & Other & 3.67 \\
\hline \multirow{4}{*}{ Number of workers } & Up to 10 & 3.83 \\
\cline { 2 - 3 } & $11-50$ & 3.60 \\
\cline { 2 - 3 } & 51-250 & 2.94 \\
\cline { 2 - 3 } & 251 or more & 4.00 \\
\hline \multirow{3}{*}{ Yearly income } & Up to 100 000 EUR & 3.83 \\
\cline { 2 - 3 } & $100000-500$ 000 EUR & 3.69 \\
\cline { 2 - 3 } & 500 000-1 000 000 EUR & 2.67 \\
\cline { 2 - 3 } & 1000001 EUR or more & 4.00 \\
\cline { 2 - 3 } & I don't know / I don't want / I cannot reveal & 3.54 \\
\hline
\end{tabular}

Based on the results of the research, top-level managers, with 251 or more workers, with a yearly income of over 1000,000 EUR, care about the green transportation most. Such results show, that green transportation is much more important in big businesses, compared to small business. The lowest moderate score to the importance of green transportation was given by the representatives of companies with 51 to 250 workers and the yearly income of 500,001 to 1000,000 EUR. 
In order to evaluate the implementation of green transportation in Šiauliai regional companies, the average estimates were calculated in points. Estimates were calculated by giving points to the answers ("yes" -3 points, "partially" - 2 points, "no" - 1 point, "I don't know" - 0 points). The calculated average estimates of applying these measures are shown in Table 4.

Table 4

\section{Implementation of green transportation}

\begin{tabular}{|l|c|}
\hline \multicolumn{1}{|c|}{ Statement } & $\begin{array}{c}\text { Average } \\
\text { estimates in } \\
\text { points }\end{array}$ \\
\hline $\begin{array}{l}\text { The company, in order to avoid downtime in traffic jam and wanting to reduce environmental } \\
\text { pollution, will choose an integrated transportation, i.e. combining several modes of } \\
\text { transportation }\end{array}$ & 2.48 \\
\hline $\begin{array}{l}\text { The company, trying to reduce transportation costs, will choose an intermediary service, i.e. } \\
\text { will buy transportation services }\end{array}$ & 1.96 \\
\hline $\begin{array}{l}\text { The company tries to use more ecological transport that does not pollute the environment as } \\
\text { much. }\end{array}$ & 1.91 \\
\hline Every year the company tries to update their transport park, to reduce environmental pollution & 1.86 \\
\hline $\begin{array}{l}\text { The company raises their drivers to drive ecologically, which reduces the transportation } \\
\text { expenses }\end{array}$ & 2.33 \\
\hline $\begin{array}{l}\text { When a company receives several orders, they plan to distribute them in a more optimal way to } \\
\text { reduce the expenses of transporting as much as possible. }\end{array}$ & 2.48 \\
\hline Management of the product return, directed towards reduction of transportation needs & 1.36 \\
\hline
\end{tabular}

Based on the survey, the Šiauliai regional companies, out of all green transportation, mostly apply integrated transportation, by combining several modes of transportation, and cargo consolidation, by combining small and large orders. Only a small part of surveyed companies tries to update their transport park and to use more ecological transport that reduces environmental pollution. The implementation of such measures requires a lot of investment, which is why only companies with bigger yearly income are capable of doing this. According to the research, the use of ecological transport and the yearly update of the transport park is implemented by medium and big companies more often. While implementing green transportation, Šiauliai regional companies try to reduce transportation needs, by implementing management of the product return, the least (see Table 4). By analysing the answers based on the type of activity companies perform, it has been noticed, that manufacturing companies are more active in implementing green transportation, compared to service and trading companies.

The benefits of green logistics encourage the implementation of green transportation. The implementation of green transportation allows to reduce the general operating expenses, reduce pollution, reduce consumption of fuel and energy, to optimize logistical flows and reduce toxic emissions (Mala et al., 2017). According to Tuzun Rad \& Gulmez (2017), green logistics improve business performance, environmental image, allows to use the resources in a more effective way. Denisa \& Zdenka (2015) draw attention to the additional environmental value. It does not just provide better environmental conditions, but also gives a better competitive advantage for the organization that chooses this path. The rating of potential benefits after implementing green transportation in Šiauliai regional companies, by giving points to the answers ("Absolutely yes" -5 points, "yes" -4 points, "neither yes nor no" -3 points, "no" -2 points, "absolutely not" -1 point). This means, that the biggest rating would show a major benefit of implementing green transportation, and if the rating was close to zero - next to no benefits. The average estimates of benefits are shown in Table 5 . 


\section{Average estimates of the benefits of green transportation}

\begin{tabular}{|l|c|}
\hline \multicolumn{1}{|c|}{ Statement } & Average estimates in points \\
\hline Improved company image & 2.58 \\
\hline Reduced fuel consumption & 2.35 \\
\hline Reduced operating costs of the company & 1.92 \\
\hline Improved results of the company & 2.15 \\
\hline Reduced air pollution & 1.32 \\
\hline Optimized distribution flows & 1.82 \\
\hline Improved cooperation with other participants in the market & 2.97 \\
\hline Competitive advantage is gained & 2.81 \\
\hline
\end{tabular}

Based on the survey above, the representatives of Siauliai regional companies most of the time do not see the potential benefits of implementing green transportation - the average rating does not exceed 3 points. The benefits of improving cooperation with other participants in the market (2.97 points), gaining competitive advantage (2.81 points) and improving company image ( 2.58 points) have been rated the highest. Even though the green transportation solutions do reduce the reparation costs of the transport and the road taxes, but the benefits of reduced expenses while implementing green transport solutions have been rated moderately (average of 1.92 points). The green transportation solutions are beneficial to the company not just for reducing expenses, but also because green logistics has the potential of increasing income and profit. This is based on the fact, that green transportation solutions open up the possibilities of working in Western Europe and thus generating bigger income. Air pollution reduction has received the lowest average rating (1.32 points), which shows, that the representatives of Siauliai regional companies notice a bigger benefit of green transportation to their company than the environment.

\section{Conclusions}

The economic, ecological and social benefits of using green transportation are: reduced emission of harmful substances, reduced pollution, reduced fuel consumption, reduced operating costs of the company, optimized distribution flows, improved results of the activity, improved company image, improved cooperation with other participants in the market, competitive advantage is gained.

Based on the research, these measures of green transportation are implemented more intensively in Siauliai regional companies: integrated transportation by combining several means of transport, cargo consolidation by combining small orders and big orders, and ecological driving.

The implementation of green transportation in Šiauliai regional companies is more important in big, not small, businesses and companies, which have bigger yearly income. While implementing green transportation, Šiauliai regional companies try to reduce transportation needs, by implementing management of the product return, the least. After comparing the implementation of green transportation in different company types, it has been noted, that manufacturing companies are the most active in implementing green transportation.

The benefits of the implementation of green transportation in Šiauliai regional companies has been rated moderately, the representatives of the companies notice a bigger benefit of green transport to their company than the environment. The biggest benefits of implementing green transportation, according to the respondents, would be improving cooperation with other participants in the market, gaining competitive advantage and improving company image, but they do not think that reducing air pollution is an important benefit.

\section{References}

Ammiruddin, S. (2020, July). Key Considerations for Effective Cargo Consolidation. Retrieved March 10, 2021, from https://sipmm.edu.sg/key-considerationsfor-effective-cargo-consolidation/.

Dey, A., LaGuardia, P., \& Srinivasan, M. (2011). Building sustainability in logistics operations: a research agenda. Management Research Review, 34(11), 1237-1259. DOI: $10.1108 / 01409171111178774$.

Dekker, R., Bloemhof, J., \& Mallidis, I. (2012). Operations Research for green logistics - An overview of aspects, issues, contributions and challenges. European Journal of Operational Research, 219(3), 671-679. DOI: 10.1016/j.ejor.2011.11.010.

Denisa, M., \& Zdenka, M. (2015). Perception of implementation processes of green logistics in SMEs in Slovakia. Procedia Economics and Finance, 26(15), 139-143. DOI: 10.1016/S2212-5671(15)00900-4. 
Donohoe, A. (2019, November). What Is Freigh Consolidation? Retrieved January 11, 2021, from https://bizfluent.com/facts-7271728-freightconsolidation-.html.

Garcia-Castro, A., \& Monzon, A. (2014). Using Floating Car Data to Analyse the Effects of ITS Measures and EcoDriving. Sensors 2014, 14(11), 21358-21374. DOI: $10.3390 / \mathrm{s} 141121358$.

Gechevski, D., Kochov, A., Popovska-Vasilevska, S., Polenakovik, R., \& Donev, V. (2016). Reverse logistics and green logistics way to improving the environmental sustainability. Acta Technica Corviniensis-Bulletin of Engineering, 9(1), 63-70. Retrieved from http://acta.fih.upt.ro/pdf/20161/ACTA-2016-1-10.pdf.

Han-ru, L. (2016). Study on Green Transportation System of International Metropolises. Procedia Engineering, 137(2016), 762-771. DOI: 10.1016/j.proeng.2016.01.314.

Karia, N., \& Asaari, M. H. A. (2016). Transforming green logistics practice into benefits: a case of third-party logistics (3PLs). Proceedings of the 2016 International Conference on Industrial Engineering and Operations Management. March 8-10, 2016, Kuala Lumpur, Malaysia.

Kengpol, A., \& Tuammee, S. (2016). The development of a decision support framework for a quantitative risk assessment in multimodal green logistics: an empirical study. International Journal of Production Research, 54(4), 1020-1038. DOI: 10.1080/00207543.2015.1041570.

Kim, Y., Lee, I., \& Kang, S. (2015). Eco Assist Techniques through Real-time Monitoring of BEV Energy Usage Efficiency. Sensors, 15(7), 14946-14959. DOI: $10.3390 / \mathrm{s} 150714946$.

Kumar, S., Teichman, S., \& Timpernagel, T. (2012). A green supply chain is a requirement for profitability. International Journal of Production Research, 50(5), 1278-1296. DOI: 10.1080/00207543.2011.571924.

Lai, K. H., \& Wong, C. W. Y. (2012). Green logistics management and performance: some empirical evidence from Chinese manufacturing exporters, Omega, 40(3), 267-282. DOI: 10.1016/j.omega.2011.07.002.

White Book of Lithuanian Regional Politics (2017). Ministry of the Interior of the Republic of Lithuania.

Mala, D., Sedlia?ikova, M., Ka??akova, A., Ben?ikova, D., Vavrova, K., \& Bikar, M. (2017). Green logistics in Slovak small and medium wood-processing enterprises. BioResources, 12(3), 5155-5173. DOI: 10.15376/biores.12.3.5155-5173.

McKinnon, A. (2010). Green logistics: the carbon agenda. LogForum, 6(3). Retrieved from https://www.logforum.net/pdf/6_3_1_10.pdf.

Nathanail, E., Terzakis, T., \& Zerzis, D. (2020). Estimating the Sustainability Impacts of an urban Consolidation certer in a Medium-Sized City. Reliability and Statistics in Transportation and Communication, 277286. DOI: 10.1007/978-3-030-44610-9 28.

Nylund, S. (2012). Reverse logistics and green logistics (master's thesis, 2012). Vaasan Ammattikorkeakoulu Vasa Yrkeshogskola University of Applied Sciences. Retrieved from https://publications.theseus.fi/bitstream/handle/10024
/46993/Reverse\%20Logistics\%20and\%20green\%201 ogistics.pdf?.

Pan, J. (2012). Research on Green Transportation and Transfer System in Urban Areas. Proceedings of the 2012 International Conference on Automobile and Traffic Science, Materials, Metallurgy Engineering (MMAT 2012). DOI: 10.2991/mmat.2013.39.

Panday, A., \& Om Bansal, H. (2014). Green transportation: need, technology and challenges. International Journal of Global Energy Issues (IJGEI), 37(5), 304-318. DOI:10.1504/IJGEI.2014.067663.

Pazirandeh, A., \& Jafari, H. (2013). Making sense of green logistics. International Journal of Productivity and Performance Management, 62(8), 889-904. DOI:10.1108/IJPPM-03-2013-0059.

Saroha, R. (2014). Green Logistics and its Significance in Modern Day Systems. International Review of Applied Engineering Research. Vol. 4(1), 89-92. Retrieved from https://www.ripublication.com/iraerspl/iraerv4n1spl_14.pdf.

Seroka-Stolka, O. (2014). The Development of Green Logistics for Implementation Sustainable Development Strategy in Companies. Procedia - Social and Behavioral Sciences, 151, 302-309. DOI: 10.1016/j.sbspro.2014.10.028.

Tuzun Rad, S., \& Gulmez, Y. S. (2017). Green logistics for sustainability. International Journal of Management Economics and Business, 13(3), 603-614. DOI:10.17130/ijmeb.2017331327.

Valančiūtė-Tonkevičienè, V., \& Pliopaitė-Bataitienè, I. (2019). Ekovairavimo pritaikymo galimybès ir potencialus aplinkosauginès naudos vertinimas. Śiuolaikinès technologijos darniai aplinkai. Mokslinès praktinès konferencijos straipsnių rinkinys, 2018/2019 m., 33-38.

Xuezhong, C., Linlin, J., \& Chengbo, W. (2011). Business process analysis and implementation strategies of greening logistics in appliances retail industry. Energy Procedia, 5, 332-336. DOI:10.1016/j.egypro.2011.03.056.

Zaman, K., \& Shamsuddin, S. (2017). Green logistics and national scale economic indicators: evidence from a panel of selected European countries. Journal of Cleaner Production, 143, 51-63.

DOI:10.1016/j.jclepro.2016.12.150.

Zhang, S., Lee, C. K. M., Chan, H. K., Choy, K. L., \& Wu, Z. (2015). Swarm intelligence applied in green logistics: a literature review. Engineering Applications of Artificial Intelligence, 37, 154-169. DOI: 10.1016/j.engappai.2014.09.007. 